Research Article

\title{
Lifetime Prevalence of Sexual Violence and Its Associated Factors among High School Female Students in Jarso District, Oromia Region, Eastern Ethiopia
}

\author{
Fufa Dufera, ${ }^{1}$ Jemal Yusuf Kebira $\mathbb{D}^{2},{ }^{2}$ Tesfaye Gobena, ${ }^{3}$ and Nega Assefa ${ }^{4}$ \\ ${ }^{1}$ Jarso District Health Office, Oromia Regional Health Bureau, Minister of Health, Ethiopia \\ ${ }^{2}$ School of Public Health, College of Health and Medical Sciences, Haramaya University, Harar, Ethiopia \\ ${ }^{3}$ Department of Environmental Health, College of Health and Medical Sciences, Haramaya University, Harar, Ethiopia \\ ${ }^{4}$ School of Nursing and Midwifery, College of Health and Medical Sciences, Haramaya University, Harar, Ethiopia
}

Correspondence should be addressed to Jemal Yusuf Kebira; jemalyusuf496@gmail.com

Received 30 June 2021; Accepted 7 December 2021; Published 27 December 2021

Academic Editor: Vikas Roy

Copyright (c) 2021 Fufa Dufera et al. This is an open access article distributed under the Creative Commons Attribution License, which permits unrestricted use, distribution, and reproduction in any medium, provided the original work is properly cited.

Background. Sexual violence is a serious public health problem affecting millions of young girls and women across the world. Recently, the issue of sexual violence against schoolgirls has garnered global and national attention with implications for health and education outcomes. Sexual violence is driven by a multitude of risk factors that occur at different levels. Understanding the magnitude, risk factors, and conceptuality of sexual violence is crucial for setting priorities and elimination efforts at different levels. Therefore, the objective of this study was to determine the lifetime prevalence of sexual violence and associated factors among high school female students in Jarso district, Oromia region, eastern Ethiopia. Methods. A school-based crosssectional study was conducted in public high schools of Jarso district, eastern Ethiopia, from $1^{\text {st }}$ March to $5^{\text {th }}$ April 2019 . A multistage sampling technique was used to select 559 eligible study participants. Data were collected by a structured selfadministered questionnaire. The outcome measure of interest was lifetime sexual violence. Bivariate and multivariable logistic regression analyses were done. Statistically significant association of variables had been declared based on the adjusted odds ratio (AOR) with its $95 \% \mathrm{CI}$ and $p$ value $<0.05$. Results. The overall magnitude of sexual violence among female students was 28.6\% (95\% CI: 25\%-32.2\%) in the study area. Forty (7.2\%) participants have experienced coercive sex against their consent. Participant's level of education $((\mathrm{AOR}=1.5,95 \% \mathrm{CI}(1.03-2.30))$, being unmarried $((\mathrm{AOR}=2.80,95 \%$ CI $(1.40-5.81))$, consumption of alcohol $((\mathrm{AOR}=3.41,95 \% \mathrm{CI}(1.11-10.40))$, using substances (hashish and/or shisha) $((\mathrm{AOR}=2.6,95 \% \mathrm{CI}$ $(1.02-6.50))$, and ever initiated sexual intercourse $((\mathrm{AOR}=5.9,95 \%$ CI $(3.3-10.7))$ were positively and statistically associated with sexual violence at $p$ value $<0.05$. Conclusion. The overall magnitude of sexual violence was relatively high $(28.6 \%)$. Thus, any intervention aimed to address sexual violence should consider the identified associated risk factors in the study area.

\section{Introduction}

Sexual violence (SV) is one of the most frequent forms of gender violence in which a person's sexual freedom is violated. It is a major public health problem affecting millions of girls and young women across the world [1]. According to the World Health Organization (WHO) estimates, 1 in 3 women aged 15-45 years worldwide experienced some form of sexual violence in their lifetime [2]. More specifically, more than 150 million young girls experienced some form of sexual violence below 18 years of age [3]. Despite the global epidemic, the prevalence of sexual violence against women is alarmingly high in developing countries, particularly in sub-Saharan Africa [4].

Approximately, one in 10 adolescents worldwide reported experiencing sexual violence [5]. Sexual violence against adolescents occurs in different circumstances, forms, and settings [6]. Adolescent schoolgirls are at risk of different forms of sexual violence by different perpetrators. Male teachers, school administrators, and students are common 
perpetrators of sexual violence against schoolgirls [7, 8]. They also experienced sexual violence at home or on the journey to and from school $[9,10]$.

Sexual violence has been found to have devastating effects on victims' health: physical, reproductive, psychological, and well-being [11-14]. Studies revealed that sexual violence against schoolgirl has negative effects on the girls' educational attainment [15-17]. Moreover, sexual violence against young girls also has a negative impact on the country's human and economic development [18-21].

Recently, the issue of sexual violence against schoolgirls has garnered global attention with implications for health and education outcomes [22-24]. With sexual violence becoming widespread in schools, the government of Ethiopia has enacted various policies and codes of conduct aimed at the prevention and control of school-related sexual violence [25-27]. In addition, the government of Ethiopia included ending violence against women in higher education as a priority concern in the second growth and transformation plan (2015-20) [28]. Furthermore, gender-responsive pedagogy addressing school-related gender-based violence through the curriculum has been implemented since 2014 [29]. Despite all these efforts, sexual violence against schoolgirls has remained the major challenge in the country's education systems, especially in high schools, with the recent studies on sexual violence among high school female students reporting that $74 \%$ and $41.6 \%$ of high school female students in central and Southwest Ethiopia, respectively, had experienced sexual violence $[30,31]$.

Sexual violence is driven by a multitude of risk factors that occur at the level of individuals, relationships, family, community, and the broader society. Consequently, understanding the magnitude, risk factors, and conceptuality of sexual violence is essential for setting priorities and elimination efforts at different levels $[3,32]$. Taking into account the prior scenario and given that most studies conducted in eastern Ethiopia have been limited to urban areas [33, 34], with no consideration of young schoolgirls in rural areas, this study is aimed at determining the lifetime prevalence of sexual violence and associated factors among high school female students of Jarso district, Oromia region, eastern Ethiopia. The findings of this study may have a vital role in influencing policymakers and different stakeholders working on sexual violence prevention in the study area.

\section{Methods}

2.1. Study Area and Period. The study was conducted in Jarso district, East Hararghe Zone, Oromia regional state, eastern Ethiopia, from $1^{\text {st }}$ March to $5^{\text {th }}$ April 2019. The Jarso District is located in eastern Oromia, $561 \mathrm{~km}$ far from Addis Ababa, the capital city of Ethiopia, and $36 \mathrm{~km}$ from the Zonal capital, Harar town. It is bounded by Kombolcha district in the West, Dire Dawa Administration in the North, Gursum District in the South, and Chinaksen District in the East. The total population (2019 projection based on the 2007 Census, CSA) of the district was 321,868, of which 163,128 were males and 158,740 were females. The district has 52 schools of which 48 are primary schools and $4 \mathrm{sec}-$ ondary schools. The educational service coverage of the district was $100 \%$ (personal communication with the head of Jarso district educational office, 2019).

2.2. Study Design, Population, and Variables. An institutional-based cross-sectional study design was employed for this study. The study's population encompassed all female students attending secondary education in selected high schools of Jarso district. Thus, a total of 559 female students who met the eligibility criteria (attending a regular program in public schools) were enrolled in the study. Female students who were absent and seriously ill during the data collection period were excluded. The measurable outcome variable under study was lifetime sexual violence against female students.

2.3. Sample Size and Sampling Procedure. The sample size for this study was calculated by a single population proportion formula $\left[n=(Z \alpha / 2)^{2} P(1-P) / d^{2}\right]$ by considering assumptions: $13.2 \%$ prevalence of sexual violence among high school female students taken from a previous similar study conducted in Dilla town, Ethiopia [35], with 95\% confidence level, $4 \%$ tolerable margin of error, design effect of 2 , and $5 \%$ expected nonresponse rate. Thus, $\left[n=2(1.96)^{2} \times\right.$ $\left.0.132(1-0.132) /(0.04)^{2}\right]=550$; considering $5 \%$ expected nonresponse rate, which is 28 , the final sample size of the study became 578 .

A multistage sampling technique was used in sampling the study participants. First, three high schools were randomly drawn from the total of four high schools in the district. Next, to achieve representativeness, the study subjects in each randomly selected high school were stratified based on their schooling level (grade 9 and grade 10). Then, the total female students in each stratum of respective high schools were identified and their sampling frame prepared. Then, proportional allocation to sample size was undertaken to determine the number of participants from each stratum (grade level) of the respective high school. Finally, study participants were selected through a simple random sampling technique using their classroom identification number as a sampling frame. Thus, the study recruited a total of 578 (328 from grade 9 and 250 from grade10) female students.

2.4. Data Collection Tools and Quality Control. Data were collected using a pretested and self-administered structured questionnaire. The questionnaire was adapted from gender-based violence tool assessment [36] and global early adolescent study tool [37] and validated by the WHO and another similar study [35]. The questionnaire consisted of the sociodemographic characteristics, family-related factors, sexual history and substance use condition, and incidence of sexual violence and its characteristics. The questionnaire was initially prepared in English and then translated into the local language (Afan Oromo). The Afan Oromo version was again translated back to English to check for any inconsistencies. Six diploma nurses and two-degree holder public health officers, a total of eight personnel participated in the data collection and supervision processes, respectively. The training was given for all personnel on the study procedures, 
data collection steps, and supervision activities, mainly focused on the responsibilities of data collectors, supervisors, and rights of respondents for two days. The questionnaire was checked for consistency and appropriateness to the study participants by conducting a pretest on $10 \%$ of the sample size at Felana high school in Kombolcha district (the nearest nonstudied district similar to the study subjects) fifteen days ahead of the actual data collection. Strict followup and supervision had been undertaken throughout the data collection period daily.

2.5. Data Processing and Analysis. Collected data were coded, entered, and cleaned using Epidata version 3.1 and exported into SPSS version 20 for analysis. Both descriptive and analytical statistics were executed. Descriptive statistics like mean, frequency, and percentage were used to describe the characteristics of participants using tables and text. To determine the association between independent and outcome variables, bivariate and multivariable logistic regression analyses were carried out. Factors found to have a $p$ value $<0.25$ in the bivariate logistic regression analysis were retained and entered into multivariable logistic regression analysis. The crude odds ratio and adjusted odds rlatio (AOR) were calculated with 95\% confidence intervals (CI). Finally, a statistical significance is considered at a $p$ value $<0.05$.

\section{Results}

3.1. Sociodemographic Characteristics of Study Participants. A total of 559 female students participated in the study, yielding a response rate of $96.7 \%$. The mean age of the study participant was 15.5 ( $\mathrm{SD} \pm 2.02$ ) years. More than half, 320 $(57.2 \%)$, of the study participants were under 15 years. The majority of participants $470(84.1 \%)$ and 533 (95.3\%) were Muslim in religion and Oromo in ethnicity, respectively. About one-third, 371 (66.4\%), of the participants were rural residents. The majority of participants 465 (83.2\%) were never married. Among those who were ever married, 56 (56.8\%) of the participants were currently in union with their partners. About three-fourths, 420 (75.1\%), of the participants' parents were living together (Table 1).

3.2. Sexual History and Substance Use Conditions of the Study Participants. More than half, 326 (58.3\%), of the participants have regular boyfriends. One hundred ninety-two $(34.3 \%)$ of the study participants have had initiated sexual intercourse with the mean age of first sexual intercourse 15.54 years. Of these, seventy-one (37\%), thirty-seven (19.3\%), and twenty-seven (14\%) participants ever had started sexual intercourse due to marriage, personal desire, and peer pressure, respectively. Among the study participants who had initiated sexual intercourse, $32(16.7 \%)$ of them have reported use of condom during their first sexual intercourse and more than half, 102 (53.1\%), of them have had initiated first sexual intercourse at the age of under 15 years. With respect to substance use, the majority, 527 (94.3\%), of the study participants did not consume alcohol while 195 (34.9\%) of them have reported using Khat (Table 2).
3.3. Prevalence and Characteristics of Sexual Violence among the Study Participants. A little over a quarter, 160 (28.6\%) (95\% CI: $25 \%-32.2 \%$ ), of the study participants have experienced some form of sexual violence at a point in their lifetime. The most common form of sexual violence experienced by participants was uninvited kiss 127 (22.7\%) followed by use of verbal abuse 115 (20.6\%). Another frequent form of sexual violence experienced by the participants involved unwelcome touching of their private parts $100(17.9 \%)$. In addition, $76(13.6 \%)$ and $40(7.2 \%)$ of the study participants have experienced, attempted, and completed coercive sex against their consent in their life, respectively. Of the total completed coercive sex cases, 17 (42.5\%) were performed at the victims' home, 15 (37.5\%) at the perpetrator's home, and $8(20 \%)$ at other sites including in schools, hotels, and forests. Boyfriends were the most claimed perpetrators of completed coercive sex cases (37.5\%), followed by relatives (30\%). Moreover, 16 (40\%) of the study participants experienced coercive sex two and above times (Table 3 ).

3.4. Factors Associated with Sexual Violence among the Study Participants. Initially, the sociodemographic characteristics of respondents, sexual history, and risk behavior, as well as family-related factors, were analyzed with bivariate logistic regression to determine factors associated with sexual violence. Next, variables that were associated with sexual violence at a $p$ value $<0.25$ in the binary logistic regression analysis were fitted into a multivariate logistic regression analysis. In the final analysis, the respondent's level of education, marital status, alcohol consumption, substance use (hashish and/or shisha), and ever engagement in sexual intercourse were positively and statistically associated with sexual violence at a $p$ value less than 0.05 .

Female students who are attending grade ten were 1.5 times more likely $(\mathrm{AOR}=1.5,95 \% \mathrm{CI}(1.03-2.30))$ to experience sexual violence than those attending grade nine. Unmarried female students were three times more likely to face sexual violence compared to their counterparts $((\mathrm{AOR}=2.80,95 \%$ CI $(1.40-5.81))$. Respondents who had drunk alcohol were three half times more likely $((\mathrm{AOR}=3.41,95 \% \mathrm{CI}(1.11-10.40))$ to experience sexual violence compared to those who had not to drink. Similarly, respondents who used substances (Hashish and/or Shisha) were 2.6 more likely $((\mathrm{AOR}=2.6,95 \% \mathrm{CI}(1.02-6.50))$ to experience sexual violence than nonusers. Moreover, female students who ever had initiated sexual intercourse were six times more likely to experience sexual violence compared to their counterparts $((\mathrm{AOR}=5.9,95 \%$ CI $(3.3-10.7))$ (Table 4).

\section{Discussion}

This study is aimed at determining the magnitude of sexual violence and associated factors among high school female students in Jarso district, eastern Ethiopia. The overall magnitude of sexual violence among the study participants was $28.6 \%$ (95\% CI: 25\%-32.2\%) in the study setting. In the final model analysis, the respondent's level of education, marital 
TABLE 1: Sociodemographic characteristics of high school female students in Jarso district, Oromia region, eastern Ethiopia, 2019 ( $n=559)$.

\begin{tabular}{|c|c|c|c|}
\hline Variables & Categories & Frequency & Percentages \\
\hline \multirow{3}{*}{ Age group } & $<15$ & 320 & 57.2 \\
\hline & $15-19$ & 210 & 37.6 \\
\hline & $>19$ & 29 & 5.2 \\
\hline \multirow{2}{*}{ Religion } & Muslim & 470 & 84.1 \\
\hline & Non-Muslim & 89 & 15.9 \\
\hline \multirow{3}{*}{ Ethnicity } & Oromo & 533 & 95.3 \\
\hline & Amhara & 22 & 3.9 \\
\hline & Others* & 4 & 0.8 \\
\hline \multirow{2}{*}{ Residence } & Urban & 188 & 33.6 \\
\hline & Rural & 371 & 66.4 \\
\hline \multirow{2}{*}{ Educational status } & Grade 9 & 317 & 56.7 \\
\hline & Grade 10 & 242 & 43.3 \\
\hline \multirow{4}{*}{ Mother's educational level } & No formal education & 318 & 56.89 \\
\hline & Primary & 103 & 18.43 \\
\hline & Secondary & 96 & 17.2 \\
\hline & College and above & 42 & 7.5 \\
\hline \multirow{4}{*}{ Father's educational level } & No formal education & 264 & 47.2 \\
\hline & Primary & 128 & 22.9 \\
\hline & Secondary & 105 & 18.8 \\
\hline & College and above & 62 & 11.1 \\
\hline \multirow{2}{*}{ Have ever married } & Yes & 94 & 16.8 \\
\hline & No & 465 & 83.2 \\
\hline \multirow{2}{*}{ Currently married (94) } & Yes & 56 & 59.6 \\
\hline & No & 38 & 40.4 \\
\hline \multirow{5}{*}{ With whom you live currently } & With parents & 416 & 74.4 \\
\hline & With friend & 39 & 7.0 \\
\hline & With husband & 39 & 7.0 \\
\hline & With relatives & 40 & 7.2 \\
\hline & Other ${ }^{* *}$ & 25 & 4.4 \\
\hline \multirow{5}{*}{ Current parental living conditions } & Mother and father live together & 420 & 75.1 \\
\hline & Separated & 79 & 14.1 \\
\hline & Only father alive & 21 & 3.8 \\
\hline & Only mother alive & 29 & 5.2 \\
\hline & Both are not alive & 10 & 1.8 \\
\hline \multirow{2}{*}{ Receive enough money } & Yes & 179 & 32.0 \\
\hline & No & 380 & 68.0 \\
\hline \multirow{3}{*}{ Monthly average family income } & $<1000 \mathrm{ETB}$ & 267 & 47.8 \\
\hline & 1000-2500 ЕТВ & 154 & 27.5 \\
\hline & $>2500$ ЕTB & 138 & 24.7 \\
\hline
\end{tabular}

Notes: ETB: Ethiopian birr; others*: Somali, Harari, and Gurage; others**: both relatives and parents, alone.

status, alcohol consumption, substance use (hashish and/or shisha), and ever-initiated sexual intercourse were positively and statistically associated with sexual violence.

Findings of the current study showed that over a quarter $(28.6 \%)$ of female students have experienced some form of sexual violence in their lifetime, which is comparable to the previous findings reported in Brazil (30.5\%) and Jima, Ethiopia $(32.4 \%)$ [38, 39]. On the other hand, the result of the current study is lower than the findings of the study conducted among in-school students in Nigeria, 41.9\%, and 
TABLE 2: Sexual history and substance use condition among high school female students in Jarso district, Oromia region, eastern Ethiopia, $2019(n=559)$.

\begin{tabular}{|c|c|c|c|}
\hline Characteristics & Categories & Frequency & Percentages \\
\hline \multirow{2}{*}{ Have regular boyfriend } & Yes & 326 & 58.3 \\
\hline & No & 233 & 41.7 \\
\hline \multirow{2}{*}{ Have you ever had sexual intercourse } & Yes & 192 & 34.3 \\
\hline & No & 367 & 65.7 \\
\hline \multirow{3}{*}{ Age at first sexual intercourse } & $<15$ & 102 & 53.1 \\
\hline & $15-17$ & 62 & 32.3 \\
\hline & $\geq 18$ & 28 & 14.6 \\
\hline \multirow{3}{*}{ Number of sexual partners (192) } & One & 56 & 29.2 \\
\hline & Two & 88 & 45.8 \\
\hline & Three and above & 48 & 25.0 \\
\hline \multirow{2}{*}{ Used condom during first sexual intercourse (192) } & Yes & 32 & 5.7 \\
\hline & No & 527 & 94.3 \\
\hline \multirow{2}{*}{ Have ever drink alcohol } & Yes & 32 & 20.6 \\
\hline & No & 444 & 79.4 \\
\hline \multirow{4}{*}{ Frequency of alcohol drinking } & Daily & 11 & 34.4 \\
\hline & $1-2 /$ week & 3 & 9.4 \\
\hline & 2-3/month & 12 & 37.5 \\
\hline & Once/month & 6 & 18.7 \\
\hline \multirow{2}{*}{ Have ever chewed Khat } & Yes & 195 & 34.9 \\
\hline & No & 364 & 65.1 \\
\hline \multirow{4}{*}{ Frequency of chewing Khat } & Daily & 65 & 33.3 \\
\hline & $1-2 /$ week & 48 & 24.6 \\
\hline & $2-3 /$ month & 36 & 18.5 \\
\hline & Once/month & 46 & 23.6 \\
\hline \multirow{2}{*}{ Have ever used substance like hashish and/or shisha } & Yes & 38 & 6.8 \\
\hline & No & 521 & 93.2 \\
\hline
\end{tabular}

South Africa, 37.9\% [40, 41], but higher than the findings of other studies conducted in Nigeria, Kenya, and Brazil, which reported $12.1 \%, 7.1 \%$, and $4 \%$ of sexual violence [42-44], respectively. This variation could be due to the differences in the measurement of sexual violence, socioeconomy, and interventions made across the countries. Higher patterns of violence against girls are common in settings with low gender equality and women empowerment $[45,46]$.

Moreover, the magnitude of sexual violence in the current study is lower than the finding of previous studies done across different regions of Ethiopia: 74\%, 68\%, 41.5\%, and $37.2 \%$ in Bishoftu and Mojo, eastern Ethiopia, Benchmaji, and Wolaita Sodo, respectively [30, 31, 33, 47]. In contrast, this study found a higher magnitude of sexual violence compared to the findings of studies conducted in Dilla town (13.2\%), Debra Markos (24.2\%), and Gurage Zone (15.9\%) $[35,48,49]$. Thus, it is generally accepted that the findings of different studies regarding the prevalence of sexual violence lack consistency across Ethiopian regions. The explanation for the inconsistency may be attributable to the differences in social perception of gender norms and culture of disclosing the incidents of sexual violence in different ethnic groups or societies across the country's regions. The incidence of sexual violence is high in societies with the prevalence of traditional gender norms that dictate behaviors and expectations for boys and girls in different ways $[50,51]$. Furthermore, the incidents of sexual violence are low in societies with a culture of choosing silence in reporting sexual violence.

The current study showed an association between sociodemographic factors and sexual violence. Unmarried female students were three times more likely to experience sexual violence than their counterparts, which is similar to the findings of the study conducted in Ethiopia and China. The study conducted in Ambo high school found that unmarried female students were three times more likely to experience sexual violence than married school girls $[52,53]$. This possibility may be due to sociocultural attitudes in society towards married women that enhance dignity and security as motherhood.

As found in this study, another sociodemographic factor significantly associated with sexual violence was the 
TABLE 3: Characteristics of sexual violence among high school female students in Jarso district, Oromia region, eastern Ethiopia, 2019 $(n=559)$.

\begin{tabular}{|c|c|c|c|}
\hline Characteristics & Categories & Frequency & Percentages \\
\hline \multirow{2}{*}{ Experienced verbal abuse that undermines one's self-esteem } & Yes & 115 & 20.6 \\
\hline & No & 444 & 79.4 \\
\hline \multirow{2}{*}{ Experienced uninvited kiss } & Yes & 127 & 22.7 \\
\hline & No & 432 & 77.3 \\
\hline \multirow{2}{*}{ Experienced unwelcoming touch like breast, genitalia area } & Yes & 100 & 17.9 \\
\hline & No & 459 & 82.1 \\
\hline \multirow{2}{*}{ Experienced forced sexual attempt without your consent } & Yes & 76 & 13.6 \\
\hline & No & 483 & 86.4 \\
\hline \multirow{2}{*}{ Experienced coercive sex without your consent } & Yes & 40 & 7.2 \\
\hline & No & 519 & 92.8 \\
\hline \multirow{3}{*}{ Place where coercive sex encountered } & Victims' home & 17 & 42.5 \\
\hline & Perpetrators' home & 15 & 37.5 \\
\hline & Others* & 8 & 20.0 \\
\hline \multirow{4}{*}{ Perpetrators of coercive sex } & Boyfriend & 15 & 37.5 \\
\hline & Husband & 6 & 15.0 \\
\hline & Relative & 12 & 30.0 \\
\hline & Others** & 7 & 17.5 \\
\hline \multirow{3}{*}{ Age of the perpetrators } & Equal to victims & 15 & 37.5 \\
\hline & Older than victim & 21 & 52.5 \\
\hline & Younger than victim & 4 & 10.0 \\
\hline \multirow{2}{*}{ Frequency of encountered forced sex in your life } & Once only & 24 & 60.0 \\
\hline & Two times and above & 16 & 40.0 \\
\hline
\end{tabular}

Notes: others ${ }^{*}$ in school, hotel, and forest; others** $=$ teacher, student, neighbor, and stranger.

respondent's level of education. Being in grade $10^{\text {th }}$ increased the risk of experiencing sexual violence by 1.5 folds compared to being in grade $9^{\text {th }}$. This finding is consistent with the finding of a study conducted in Nekemte high school where being grade $10^{\text {th }}$ increased the risk of experiencing sexual violence by 2.8 folds compared to their counterparts [54]. But, contrary to the current finding, the study conducted in China and Uganda revealed that the likelihood of experiencing sexual violence decreases with increased grade attainment [23, 53]. This variation could be due to the differences in educating the schoolgirls about sexual issues according to their age and level of grade across countries.

The current study found that female students who used substances, either hashish or shisha, were 2.6 times more likely to be sexually violated compared to their counterparts. This finding is consistent with the finding of a study conducted in China among high school students, which reported that students using drugs like cocaine and shisha were two times more likely to be sexually violated compared to their counterparts [55]. The reason behind this association may be due to the fact that drugs can alter the takers' consciousness and motivate for violence. In addition, shisha is easily accessible in the study area nexus to Khat (local stimulant), and that the perpetrators who used these substances eventually commit sexual violence.
Ever consumption of alcohol was significantly associated with sexual violence in the present study. Female students who had a history of alcohol consumption were 3.41 times more likely to experience sexual violence compared to students who had not a history of alcohol consumption. This finding is in line with other studies conducted in Ethiopia and elsewhere. A study conducted in China, Brazil, and South Africa found that female students who consumed alcohol were at increased risk of experiencing sexual violence compared to their counterparts [41, 43, 55]. Likewise, a study conducted in Debra Markos, Dilla town, Hadiya Zone, and Nekemte town, Ethiopia, revealed that alcohol consumption was one of the risk factors contributing to sexual violence among school girls [35, 48, 54, 56]. The possible reason may be schools are alcohol-free so perpetrators take females to a secret place where easily accessible to alcohol which enables them to be susceptible to violence.

Furthermore, the current study found ever having had sexual intercourse was associated with sexual violence. Female students who ever have had sexual intercourse were six times more likely to experience sexual violence than those who had not had sexual intercourse and is in line with the study done in Dilla and Nekemte high school $[35,54]$, which reported that female students who ever had sexual intercourse were five and six times more likely to experience 
TABLE 4: Factors associated with sexual violence among high school female students in Jarso district, Oromia region, eastern Ethiopia, 2019 $(n=559)$.

\begin{tabular}{|c|c|c|c|c|c|}
\hline \multirow[t]{2}{*}{ Variables } & \multirow[t]{2}{*}{ Categories } & \multicolumn{2}{|c|}{$\begin{array}{l}\text { Sexually } \\
\text { violated? }\end{array}$} & \multirow[t]{2}{*}{ COR $(95 \% \mathrm{CI})$} & \multirow[t]{2}{*}{$\operatorname{AOR}(95 \% \mathrm{CI})$} \\
\hline & & Yes & No & & \\
\hline \multirow{3}{*}{ Age } & $<15$ & 103 & 217 & $1.55(1.04-2.33)^{*}$ & $1.15(0.74,1.8)$ \\
\hline & $15-19$ & 46 & 164 & $2.44(.98-3.11)$ & $1.23(0.44-2.58)$ \\
\hline & $>19$ & 11 & 18 & Ref. & Ref. \\
\hline \multirow{2}{*}{ Educational status } & Grade 10 & 84 & 158 & $1.69(1.2-2.4)^{*}$ & $1.5(1.03-2.3)^{* *}$ \\
\hline & Grade 9 & 76 & 241 & Ref. & Ref. \\
\hline \multirow{4}{*}{ Mother's educational level } & No formal education & 117 & 201 & $3.01(1.05-6.1)^{*}$ & $1.60(0.66-3.90)$ \\
\hline & Primary & 25 & 78 & $1.7(0.74-3.80)$ & $1.01(0.45-2.23)$ \\
\hline & Secondary & 18 & 78 & $0.88(0.67-1.2)$ & $1.2(0.51-2.80)$ \\
\hline & College and above & 10 & 32 & Ref. & Ref. \\
\hline \multirow{4}{*}{ Father's educational level } & No formal education & 94 & 170 & $1.35(1.02-2.4)^{*}$ & $0.29(0.06-1.45)$ \\
\hline & Primary & 32 & 96 & $1.37(0.99-1.9)$ & $0.43(0.9-1.91)$ \\
\hline & Secondary & 25 & 80 & $1.35(0.95-1.9)$ & $0.37(0.08-1.76)$ \\
\hline & College and above & 9 & 53 & Ref. & Ref. \\
\hline \multirow{5}{*}{ Currently living condition } & With mother and father & 95 & 322 & Ref. & Ref. \\
\hline & With friends & 20 & 19 & $3.6(1.85-7.04)^{*}$ & $1.5(0.57-3.92)$ \\
\hline & With husband & 15 & 24 & $2.1(1.1-4.20)^{*}$ & $0.83(0.21-2.15)$ \\
\hline & With relatives & 18 & 22 & $0.88(0.71-1.12)$ & $2.1(.97-3.8)$ \\
\hline & Others** & 13 & 12 & $3.7(1.6-8.4)^{*}$ & $0.25(0.23-1.22)$ \\
\hline \multirow{5}{*}{ Current parental living condition } & Live together & 100 & 320 & Ref. & Ref. \\
\hline & Separated & 33 & 46 & $2.3(1.4-3.80)^{*}$ & $1.14(.59-3.61)$ \\
\hline & Only father alive & 7 & 14 & $1.6(0.63-4.07)$ & $2.04(0.75-5.46)$ \\
\hline & Only mother alive & 16 & 13 & $3.94(1.83-8.5)^{*}$ & $2.1(0.81-6.01)$ \\
\hline & Both are not alive & 4 & 6 & $2.13(0.58-7.7)$ & $2.45(0.7-9.4)$ \\
\hline \multirow{2}{*}{ Marital status } & Married & 36 & 58 & Ref. & Ref. \\
\hline & Unmarried & 124 & 341 & $0.58(0.39,0.93)^{*}$ & $2.80(1.4-5.80)^{* *}$ \\
\hline \multirow{2}{*}{ Ever drink alcohol } & Yes & 23 & 9 & $7.28(3.31-16.1)^{*}$ & $3.41(1.1-10.4)^{* *}$ \\
\hline & No & 137 & 390 & Ref. & Ref. \\
\hline \multirow{2}{*}{ Ever chew Khat } & Yes & 91 & 104 & $3.75(2.51-5.45)^{*}$ & $1.45(0.9-2.32)$ \\
\hline & No & 69 & 295 & Ref. & Ref. \\
\hline \multirow{2}{*}{ Ever use substances like shisha or hashish } & Yes & 27 & 11 & $7.21(3.45-14.80)^{*}$ & $2.6(1.02-6.50)^{* *}$ \\
\hline & No & 133 & 388 & Ref. & Ref. \\
\hline \multirow{2}{*}{ Had ever started sexual intercourse } & Yes & 106 & 86 & $7.14(4.76-10.7)^{*}$ & $5.9(3.3-10.7)^{* *}$ \\
\hline & No & 54 & 313 & Ref. & Ref. \\
\hline \multirow{3}{*}{ Monthly average family income } & $<1000$ ETB & 60 & 207 & $1.7(1.05-2.8)^{*}$ & $1.22(0.75-1.98)$ \\
\hline & $1000-2500$ ЕTB & 81 & 73 & $1.14(0.74-1.74)$ & $0.70(0.4-1.22)$ \\
\hline & $>2500$ ETB & 19 & 119 & Ref. & Ref. \\
\hline
\end{tabular}

Notes: ${ }^{*}$ significant at $p$ value $<0.05$ for COR; ${ }^{* *}$ significant at $p$ value $<0.05$ for AOR; ETB: Ethiopian birr; CI: confidence interval; COR: crude odd ratio; AOR: adjusted odd ratio; others** $=$ both relatives and parents, alone.

sexual violence than their counterparts, respectively. Sexual violence in this study includes sexual experiences that female students were forced to participate in, including rape, and this could explain the increased risk of sexual violence among those who had had sexual intercourse. In addition, the possible explanation for this association may be those 
who had previous sexual experience might be easily approachable and be susceptible to conditions of violence as many of them were victimized by their boyfriends.

\section{Conclusion}

The overall magnitude of sexual violence among the study participants was 28.6\% (95\% CI: 25\%-32.20\%), of which forty $(7.2 \%)$ participants have experienced coercive sex against their consent in their life. Boyfriends were the major perpetrators of forced sex. The respondent's level of education, marital status, alcohol consumption, substance use (hashish and/or shisha), and ever engagement in sexual intercourse were significantly associated with sexual violence. Therefore, it will be crucial if any proposed intervention aimed to address sexual violence shall consider the factors that were identified in the study area.

5.1. Limitations of the Study. The study may be exposed to social desirability and recall bias because the study was conducted on very sensitive, private issues and lifetime experience. Being a cross-sectional study design, this study does not establish cause-effect relationships between the study variables. In addition, this study recruited a limited sample size, and hence, the finding of this study may not be generalizable to female students in Ethiopia. Furthermore, the study was not incorporated qualitative interpretation of sexual violence.

\section{Abbreviations}

AOR: Adjusted odds ratio

CI: Confidence interval

COR: Crude odds ratio

ETB: Ethiopian birr

SD: Standard deviation

SPSS: Statistical Package for Social Science

$\mathrm{km}$ : Kilometer.

\section{Data Availability}

Data is available upon request from the corresponding author.

\section{Ethical Approval}

The study complied with the Helsinki Declaration of research involving human subjects and fulfilled the requirements of the Ethiopian National Health Research and Ethics guideline. The study was also approved by the Institutional Health Research ethics review committee (IHRERC), College of Health and Medical Sciences, Haramaya University, Ethiopia (Ref. no: IHRERC/050/2019) written on 22, February 2019.

\section{Consent}

After being introduced to the purpose of the study, both verbal and signed informed consent was obtained from participants. For participants under 18 years, signed informed consent was obtained from their parents or guardians. Data confidentiality was maintained through an anonymous questionnaire.

\section{Conflicts of Interest}

The authors declare that they have no conflict of interests.

\section{Authors' Contributions}

FD, JYK, TG, and NA made a significant contribution to the conception of the idea, participated in the development and amendment of the proposal, participated in data collection and analysis and interpretations of results, and reviewed and edited the manuscript for intellectual contents. JYK wrote the original draft of the manuscript. All authors read and agreed to publish the final version of the manuscript.

\section{Acknowledgments}

The authors would like to thank Haramaya University, College of Health and Medical Sciences for providing an opportunity to conduct this study. We also like to thank the East Hararghe Zone education bureau and Jarso district education center administration and respective high school staffs for their genuine help throughout the data collection process.

\section{Supplementary Materials}

Questionnare. (Supplementary Materials)

\section{References}

[1] C. García-Moreno, C. Pallitto, K. Devries, H. Stöckl, C. Watts, and N. Abrahams, Global and regional estimates of violence against women: prevalence and health effects of intimate partner violence and non-partner sexual violence, World Health Organization, 2013.

[2] Organization, WH, Violence against women prevalence estimates, 2018: global, regional and national prevalence estimates for intimate partner violence against women and global and regional prevalence estimates for non-partner sexual violence against women, World Health Organization., 2021.

[3] E. G. Krug, J. A. Mercy, L. L. Dahlberg, and A. B. Zwi, "The world report on violence and health," The Lancet, vol. 360, no. 9339, pp. 1083-1088, 2002.

[4] T. Palermo, J. Bleck, and A. Peterman, "Tip of the iceberg: reporting and gender-based violence in developing countries," American Journal of Epidemiology, vol. 179, no. 5, pp. 602$612,2014$.

[5] K. Wincentak, J. Connolly, and N. Card, "Teen dating violence: a meta-analytic review of prevalence rates," Psychology of Violence, vol. 7, no. 2, pp. 224-241, 2017.

[6] E. Dartnall and R. Jewkes, "Sexual violence against women: the scope of the problem," Best practice \& Research Clinical Obstetrics \& Gynaecology, vol. 27, no. 1, pp. 3-13, 2013.

[7] M. Dunne, S. Humphreys, and F. Leach, "Gender violence in schools in the developing world," Gender and Education, vol. 18, no. 1, pp. 75-98, 2006. 
[8] L. Antonowicz, Too often in silence: a report on school-based violence in West and Central Africa, UNICEF, Plan West Africa, Save the Children Sweden West Africa and Action Aid, 2010.

[9] M. L. Le Mat, “'Sexual violence is not good for our country's development'. Students' interpretations of sexual violence in a secondary school in Addis Ababa, Ethiopia," Gender and Education, vol. 28, no. 4, pp. 562-580, 2016.

[10] N. A. L. S. Salter, Violence free zone: end school-related violence, Global AIDS Alliance, Washington, DC, 2007.

[11] F. Mason and Z. Lodrick, "Psychological consequences of sexual assault," Best Practice \& Research Clinical Obstetrics \& Gynaecology, vol. 27, no. 1, pp. 27-37, 2013.

[12] R. Jina and L. S. Thomas, "Health consequences of sexual violence against women," Best Practice \& Research Clinical Obstetrics \& Gynaecology, vol. 27, no. 1, pp. 15-26, 2013.

[13] C. M. Williams, E. R. Clear, and A. L. Coker, "Sexual coercion and sexual violence at first intercourse associated with sexually transmitted infections," Sexually Transmitted Diseases, vol. 40, no. 10, pp. 771-775, 2013.

[14] S. Bott, Sexual violence and coercion: implications for sexual and reproductive health. Social determinants of sexual and reproductive health: informing future research and programme implementation, World Health Organization, Geneva, 2010.

[15] S. Potter, R. Howard, S. Murphy, and M. M. Moynihan, "Longterm impacts of college sexual assaults on women survivors' educational and career attainments," Journal of American College Health, vol. 66, no. 6, pp. 496-507, 2018.

[16] D. Eisenberg, E. Golberstein, and J. B. Hunt, "Mental health and academic success in college," The BE Journal of Economic Analysis \& Policy, vol. 9, no. 1, 2009.

[17] Save the Children Denmark, MoEMoWsA, Addis Abeba, A Study on Violence against Girls in Primary Schools and Its Impacts on Girls', Education in Ethiopia, 2008.

[18] J. True, The political economy of violence against women, Oxford University Press, 2012.

[19] R. M. Loya, "Rape as an economic Crime," Journal of Interpersonal Violence, vol. 30, no. 16, pp. 2793-2813, 2015.

[20] D. Bolger, "Gender violence costs: schools' financial obligations under title IX," Yale LJ, vol. 125, 2015.

[21] M. H. Weiner, "Legal counsel for survivors of campus sexual violence," Yale JL \& Feminism, vol. 29, 2017.

[22] A. Y. Badri, "School-gender-based violence in Africa: prevalence and consequences," Global Journal of Arts Humanities and Social Sciences, vol. 2, no. 2, pp. 1-20, 2014.

[23] J. A. Behrman, A. Peterman, and T. Palermo, "Does keeping adolescent girls in school protect against sexual violence? Quasi-experimental evidence from east and southern Africa," Journal of Adolescent Health, vol. 60, no. 2, pp. 184-190, 2017.

[24] International, MS, Are Schools Safe Havens for Children? Examining School-Related Gender-Based Violence, US Agency for International Development Washington, DC, 2008.

[25] J. L. N. Parkes, J. Heslop, F. Johnson Ross, R. Westerveld, and E. S. Unterhalter, "Addressing SRGBV in Ethiopia: a scoping study of policy and practice to reduce gender-based violence in and around schools," in UCL Institute of Education, London, UK, 2017.

[26] J. Heslop, J. Parkes, F. Johnson Ross, F. Alito, and E. Turner, "The code of conduct on prevention of school-related gender-based violence: a study of policy enactment in Ethiopia," in UCL Institute of Education, London, UK, 2019.
[27] Federal Democratic Republic of Ethiopia Ministry of Women, MoWCYA, National Strategy and Action Plan on Harmful Traditional Practices (HTPs) against Women and Children in Ethiopia, Addis Ababa, Ministry of Women, Children and Youth Affairs (MoWCYA), 2013.

[28] M. Singh, "Women empowerment in public higher education institutions in Ethiopia," Journal of Developing country studies, vol. 9, no. 4, 2019.

[29] Federal Democratic Republic of Ethiopia, MOE, Gender strategy for the education and training sector, Addis Ababa, Ministery of Education (MOE), 2014.

[30] S. Fekadu Mekonnen and S. Garoma Abeya, "Sexual violence and associated factors among female students of preparatory schools in Modjo and Bishoftu towns of East Showa Zone, Oromia state, Ethiopia," Rehabilitation, vol. 4, no. 3, pp. 4453, 2019.

[31] S. Mulugeta, A. Meleko, A. Tamiru, E. Elsaye, and Y. Bergena, "Prevalence of sexual violence and its characteristics among female students in Aman high school, Bench Maji Zone, south west Ethiopia-a descriptive cross sectional study, 2017," Scholars Journal of Applied Medical Sciences, vol. 5, 2017.

[32] J. Parkes and E. Unterhalter, Hope and history: education engagements with poverty, inequality and gender violence, Routledge, 2015.

[33] A. B. Bekele, M. A. G. van Aken, and J. S. Dubas, "Sexual violence victimization among female secondary school students in eastern Ethiopia," Violence and Victims, vol. 26, no. 5, pp. 608-630, 2011.

[34] J. M. Cafo, A. S. Demisie, and B. B. Abera, "Assessment of sexual violence and associated factors among high school students in Harari regional state, Harar town, eastern Ethiopia," Science Research, vol. 2, no. 5, pp. 91-97, 2014.

[35] T. Desalegn, B. Balcha, and A. Yigrem, "Prevalence and associated factors of sexual violence among high school female students in Dilla town, Gedeo zone SNNPR, Ethiopia," Epidemiology: Open Access, vol. 7, 2017.

[36] C. García-Moreno, H. A. Jansen, M. Ellsberg, L. Heise, and C. Watts, WHO multi-country study on women's health and domestic violence against women, World Health Organization, 2005.

[37] World Health Organization, "Global early adolescent study questionnaire," 2019, https://www.geastudy.org/downloadthe-measures.

[38] M. D. J. Santos, M. D. M. Mascarenhas, M. T. P. Rodrigues, and R. A. Monteiro, "Caracterização da violência sexual contra crianças e adolescentes na escola - Brasil, 2010-2014," Epidemiologia e Serviços de Saúde, vol. 27, no. 2, article e2017059, 2018.

[39] I. Bekele, W. Zewde, and A. Neme, "Assessment of prevalence, types and factors associated with adolescent sexual abuse in high school in Limmu Gnet High School," Health Science Journal, vol. 11, no. 3, 2017.

[40] M. O. Kunnuji and A. Esiet, "Prevalence and correlates of sexual abuse among female out-of-school adolescents in Iwaya community, Lagos state, Nigeria," African Journal of Reproductive Health, vol. 19, no. 1, pp. 82-90, 2015.

[41] A. I. Ajayi, E. Mudefi, and E. O. Owolabi, "Prevalence and correlates of sexual violence among adolescent girls and young women: findings from a cross-sectional study in a South African university.", BMC Women's Health, vol. 21, 2020. 
[42] O. Oladepo, O. Yusuf, and O. Arulogun, "Factors influencing gender based violence among men and women in selected states in Nigeria," African Journal of Reproductive Health, vol. 15, no. 4, pp. 78-86, 2011.

[43] M. D. J. Santos, M. D. M. Mascarenhas, D. C. Malta, C. M. Lima, and M. M. A. . Silva, "Prevalência de violência sexual e fatores associados entre estudantes do ensino fundamental Brasil, 2015," Ciência \& Saúde Coletiva, vol. 24, no. 2, pp. 535-544, 2019.

[44] B. O. Orindi, B. W. Maina, S. W. Muuo et al., "Experiences of violence among adolescent girls and young women in Nairobi's informal settlements prior to scale-up of the DREAMS partnership: prevalence, severity and predictors," PLoS One, vol. 15, no. 4, article e0231737, 2020.

[45] C. Garcia-Moreno, H. A. F. M. Jansen, M. Ellsberg, L. Heise, and C. H. Watts, "Prevalence of intimate partner violence: findings from the WHO multi-country study on women's health and domestic violence," The Lancet, vol. 368, no. 9543 , pp. 1260-1269, 2006.

[46] J. Archer, "Cross-cultural differences in physical aggression between partners: a social-role analysis," Personality and Social Psychology Review, vol. 10, no. 2, pp. 133-153, 2006.

[47] T. Tantu, S. Wolka, M. Gunta, M. Teshome, H. Mohammed, and B. Duko, "Prevalence and determinants of gender-based violence among high school female students in Wolaita Sodo, Ethiopia: an institutionally based cross-sectional study," BMC Public Health, vol. 20, pp. 1-9, 2020.

[48] G. Mullu, A. Gizachew, D. Amare et al., "Prevalence of gender based violence and associated factors among female students of Menkorer high school in Debre Markos town, Northwest Ethiopia," Science, vol. 3, no. 1, pp. 67-74, 2015.

[49] Z. Bisrat, A. Kenzudine, and H. Zerihun, "Correlates of sexual and physical violence among female preparatory school students in Gurage zone, Ethiopia," Journal of Womens Health, Issues and Care ISSN, vol. 5, 2017.

[50] J. Pulerwitz, L. Hughes, M. Mehta, A. Kidanu, F. Verani, and S. Tewolde, "Changing gender norms and reducing intimate partner violence: results from a quasi-experimental intervention study with young men in Ethiopia," American Journal of Public Health, vol. 105, no. 1, pp. 132-137, 2015.

[51] K. Hardee, J. Gay, M. Croce-Galis, and A. Peltz, "Strengthening the enabling environment for women and girls: what is the evidence in social and structural approaches in the HIV response?," Journal of the International AIDS Society, vol. 17, no. 1, article 18619, 2014.

[52] E. Eshetu, “Assessment of sexual harassment and associated factors among grade 9-12 female students at schools in ambo district, Oromia national regional state, Ethiopia," Science Journal of Public Health, vol. 3, no. 1, pp. 97-100, 2015.

[53] J. Wu, L. Wang, G. Zhao, and X. Zhang, "Sexual abuse and reproductive health among unmarried young women seeking abortion in China," International Journal of Gynecology \& Obstetrics, vol. 92, no. 2, pp. 186-191, 2006.

[54] K. Bidu and Z. Babure, "Assessment of sexual abuse and associated factors among adolescents in high schools, Nekemte town, east Wollega zone, Oromia regional state, Western Ethiopia, 2017," The Journal of Nursing Care, vol. 7, no. 457, 2018.
[55] Y. Song, C.-Y. Ji, and A. Agardh, "Sexual coercion and healthrisk behaviors among urban Chinese high school students," Global Health Action, vol. 7, no. 1, article 24418, 2014.

[56] T. Letta, A. Feleke, and L. Derseh, "Assessment of violence and associated factors among rural high school female students, in Hadiya zone, southern nation and nationalities peoples' region, Ethiopia, 2013," OALib, vol. 1, no. 3, pp. 1-14, 2014. 